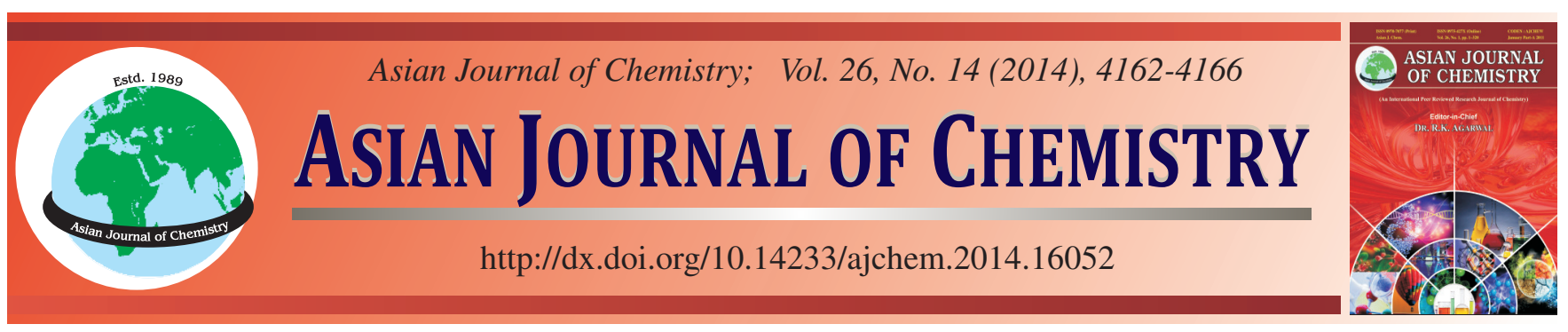

\title{
Simultaneous Determination of Eight Preservatives in Feeds by High Performance Liquid Chromatography
}

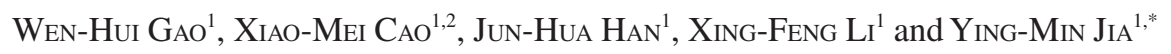

${ }^{1}$ College of Biological Science and Engineering, Hebei University of Science and Technology, Shijiazhuang 050018, P.R. China

${ }^{2}$ Research Centre of Quality and Safety of Agro-Products, Hebei Academy of Agriculture and Forestry Sciences, Shijiazhuang 050051, P.R. China

*Corresponding author: E-mail: ymjia0311@ hebust.edu.cn

\begin{abstract}
A high performance liquid chromatography method for the separation and determination of eight preservatives benzoic acid, sorbic acid and six parabens in feeds was developed and validated. The condition of sample preparation was $50 \%$ methanol and $50 \%$ water (v/v) extraction of the feeds. The experiment was carried out with the mobile phase of methanol- $0.05 \mathrm{~mol} / \mathrm{L}$ ammonium formate aqueous solution ( $\mathrm{pH} 4.5$ ) using gradient elution at $245 \mathrm{~nm}$. Under optimized conditions, the eight preservatives were separated successfully within $13 \mathrm{~min}$. The correlation coefficients were more than 0.9991 and the detection limits were in the range of 0.05 and $0.5 \mu \mathrm{g} / \mathrm{mL}$. The average recoveries of the eight preservatives were between 80.8 and $107.4 \%$. The relative standard deviations (RSDs) were less than $5.0 \%(\mathrm{n}=5)$. The proposed HPLC method is sensitive, reliable, fast and can be applied to quality control test of preservatives in feeds.
\end{abstract}

Keywords: Feed, Preservative, High performance liquid chromatography.

\section{INTRODUCTION}

In recent years, with the expansion of the feed industry and the increase of feed output, more and more feed products are produced and saled. However, during storage or transportation, lots of feeds become rancidity and deterioration due to the micro-organisms. As a result, the quality of feeds directly affects of animal product quality and the food safety.

Preservatives are used in feed products to protect the quality of feeds and to maintain the potency and stability of the product formulation. Benzoic acid (BA), sorbic acid (SA), parabens including methyl paraben (MP), ethyl paraben (EP), propyl paraben (PP), iso-propyl paraben (IPP), butyl paraben (BP), iso-butyl paraben (IBP) are commonly used as preservatives because of their antibiosis properties.

Sorbic acid is widely used in foods and feeds due to its low price and excellent inhibitory effect on mold and yeast. Benzoic acid has a broad antimicrobial spectrum, except the acid-forming bacteria. Compared with benzoic acid, parabens exhibit stronger inhibition effect with relatively low toxicity, good stability and nonvolatility ${ }^{1}$. Another advantage of parabens is the $\mathrm{pH}$ and temperature stability. Generally, the antimicrobial activity of parabens also increases as length of the alkyl chain from methyl to $n$-butyl increase. But in practice, shorter esters have been commonly used because their higher water solubility than that of the long alkyl chain esters ${ }^{2}$.
However, the residue of preservatives in animal products is harmful to human body. Some preservatives such as methyl paraben or ethyl paraben have potential risks of causing diseases, such as erythema or allergic contact dermatitis ${ }^{3}$. Moreover, parabens show estrogenic activity ${ }^{2}$. Sorbic acid and benzoic acid also have some known toxicity ${ }^{4}$. Consequently, the analytical determination of these preservatives is not only important for quality control purposes but also for consumer interest and protection.

In many cases, more than one preservative is added for better effectiveness. However, the reported methods for sorbic acid, benzoic acid and parabens determination in foods, medicine or cosmetic were high performance liquid chromatography $^{5-10}$, liquid chromatography-mass spectrometry ${ }^{11}$, gas chromatography ${ }^{12}$, gas chromatography-mass spectrometry ${ }^{13,14}$ or micellar electrokinetic capillary chromatography ${ }^{15-17}$. Saad et al. ${ }^{18}$ reported that benzoic acid, sorbic acid, methyl paraben and propyl paraben in foodstuffs could be simultaneously determined by using HPLC. The separation of the four components was achieved in less than 23 min using a mobile phase of methanol-acetate buffer ( $\mathrm{pH} 4.4)$. The good recoveries of 102-106\% were obtained. However, there were few reports on simultaneous determination of the eight preservatives, including sorbic acid, benzoic acid, methyl paraben, ethyl paraben, butyl paraben, propyl paraben, iso-butyl paraben and iso-propyl paraben. Although these preservatives in soysauce 
was detected within $0.5 \mathrm{~h}$ by HPLC using acetonitrile- $0.01 \mathrm{~mol} /$ $\mathrm{L}$ potassium dihydrogen phosphate solution $(\mathrm{pH}=4)$ as mobile phase, the determination time was too long. In particular, propyl paraben and iso-propyl paraben were not separated completely ${ }^{19}$. Therefore, it is necessary to develop a sensitive, reliable, fast method for the assay of these preservatives in feed products by HPLC.

The objective of the present work was to develop a fast and sensitive method for the simultaneous determination of the eight preservatives (sorbic acid, benzoic acid, methyl paraben, ethyl paraben, propyl paraben, iso-propyl paraben, butyl paraben and iso-butyl paraben) by HPLC. In addition, the feasibility of this method was evaluated by investigating detection limit, linear range, recovery, etc.

\section{EXPERIMENTAL}

Formic acid, acetic acid, ammonium acetate, ammonium formate, acetonitrile and ethanol were of analytical-reagent grade and methanol was HPLC grade (Concord, China). Benzoic acid (BA), sorbic acid (SA), methyl paraben (MP), ethyl paraben (EP), propyl paraben (PP), iso-propyl paraben (IPP), butyl paraben (BP) and iso-butyl paraben (IBP) were purchased from Sigma-Aldrich (St. Louis, MO, USA). Water was deionized and purified on Milli-Q water purification system (Barnstead D3750, Thermo, USA).

Experiments were carried out on a Shimadzu HPLC 20A system with a solvent delivery pump system model LC-20AB, an online degasification system model DGU-20A 3 , a column thermostat oven model CTO-10AS and an UV-visible detector model SPD-20A (Shimadzu Corporation, Japan). KH5200 ultrasonicator (Kunshan, China), Milli-Q water purification system (Barnstead D3750, Thermo, USA) and LD5-2A centrifuge (Leiboer, China) were used in the experiment. The chromatographic column used was a Promosil $\mathrm{C}_{18}, 4.6 \mathrm{~mm} \times$ $150 \mathrm{~mm}$ i.d. with $5 \mu \mathrm{m}$ particle diameter (Agela Technologies).

Preparation of standard solution: Stock solutions of all analytes (1 mg/mL each) were prepared in methanol (HLPC grade) and were diluted to the desired concentration with methanol. The mixture solutions were diluted in a $25 \mathrm{~mL}$ volumetric flask, including $0.13 \mathrm{~mL}$ sorbic acid, $2 \mathrm{~mL}$ benzoic acid, $2.5 \mathrm{~mL}$ methyl paraben, $2.5 \mathrm{~mL}$ ethyl paraben, $3 \mathrm{~mL}$ propyl paraben, $4 \mathrm{~mL}$ butyl paraben, $2.5 \mathrm{~mL}$ iso-propyl paraben and $3 \mathrm{~mL}$ iso-butyl paraben. Suitable working solutions with concentration in the range of $0.05-200 \mu \mathrm{g} / \mathrm{mL}$ were prepared as standard calibration solutions. The calibration curves were plots of area $v s$. concentration. Before used, all the solutions were filtered through $0.45 \mu \mathrm{m}$ membrane.

Chromatographic conditions: The mobile phase was constituted of methanol and $0.05 \mathrm{~mol} / \mathrm{L}$ ammonium formate aqueous solution ( $\mathrm{pH} 4.5$ ). The gradient elution condition was $55 \%$ methanol for $2 \mathrm{~min}$, after which it was changed to $65 \%$ methanol for $1 \mathrm{~min}$, then continued to $15 \mathrm{~min}$. The flow rate was $1 \mathrm{~mL} / \mathrm{min}$ and the injection volume was $5 \mu \mathrm{L}$. The detection wavelength was set at $245 \mathrm{~nm}$. All the analysis were performed at $25^{\circ} \mathrm{C}$.

Preparation of feed samples: The feed samples were supplied by Hebei Institute of Food Quality Supervision, Inspection and Research (Shijiazhuang, China).
For the preparation of sample solution, an amount of the feed $(1 \mathrm{~g})$ was accurately weighted into a $25 \mathrm{~mL}$ glass tube and dissolved into $10 \mathrm{~mL}$ of extraction solvent (methanol: water $=50: 50, \mathrm{v} / \mathrm{v})$. Samples were extracted using a sonifier (Kunshan, China) for 25 min and then centrifuged at 4000 $\mathrm{rpm}$ for $5 \mathrm{~min}$. Before used, all solutions were filtered through $0.45 \mu \mathrm{m}$ membrane.

\section{RESULTS AND DISCUSSION}

Optimization of sample preparation conditions: In order to get the best extraction efficiency, different extractants of methanol-water and ethanol-water under different ratios were evaluated. Peak area can directly reflect the extraction efficiency of the studied components. As can be seen from Fig. 1, A and B, the extraction efficiency of $50 \%$ methanol$50 \%$ water (v/v) and $30 \%$ ethanol-70 \% water (v/v)was better than the other ratios. From Fig. 1, C, it revealed that the extraction efficiency of 50\% methanol-50\% water $(\mathrm{v} / \mathrm{v})$ was higher than that of $30 \%$ ethanol-70\% water (v/v). In addition, the ultrasonication time was considered. The results showed that the peak area of the studied components increased with the ultrasonication time from 5 to $25 \mathrm{~min}$, but it didn't increase obviously after $25 \mathrm{~min}$. So, the best extractant was determined as $50 \%$ methanol-50\% water (v/v) and the optimal ultrasonication time was determined to be $25 \mathrm{~min}$.

Optimization of detection wavelength: The UV absorption spectrum of the eight preservatives were shown in Fig. 2. The maximum wavelength of the preservatives was $226 \mathrm{~nm}$ for benzoic acid, $256 \mathrm{~nm}$ for sorbic acid and six parabens, respectively. At $256 \mathrm{~nm}$, there was no absorption for benzoic acid. In order to obtain good sensitivity for the eight preservatives, a compromise choice of detection wavelength should be made. Through different wavelength experiments, the detector wavelength was kept constant at $245 \mathrm{~nm}$.

Optimization of mobile phases: In order to obtain the best separation of the eight preservatives, different mobile phases were investigated, including methanol-water, methanol$0.05 \mathrm{~mol} / \mathrm{L}$ ammonium acetate solution and methanol-0.05 $\mathrm{mol} / \mathrm{L}$ ammonium formate solution under different ratios. Both methanol-water and methanol-0.05 mol/L ammonium acetate solution did not provide satisfactory chromatographic profiles. The peak of benzoic acid was a before-stretch peak and the three peaks of benzoic acid, sorbic acid and methyl paraben were too tight when methanol-water was used as mobile phase. There were baseline drifts after the peak of ethyl paraben when methanol-0.05 mol/L ammonium acetate was used as mobile phase. In contrast, using methanol-0.05 mol/L ammonium formate solution as mobile phase, there was no such phenomenon mentioned above. As a result, methanol- $0.05 \mathrm{~mol} / \mathrm{L}$ ammonium formate solution was selected as the appropriate mobile phase.

The ratio of mobile phase had a great impact on the separation of the studied components. At the beginning of the experiment, the volume ratio of methanol- $0.05 \mathrm{~mol} / \mathrm{L}$ ammonium formate solution $(45: 55,55: 45,65: 35, \mathrm{v} / \mathrm{v})$ was tested using isocratic elution. The results showed that the separation time was nearly 80 min under the ratio of 45:55 and the peaks of parabens were low and wide. Under the ratio of $65: 35$, the 

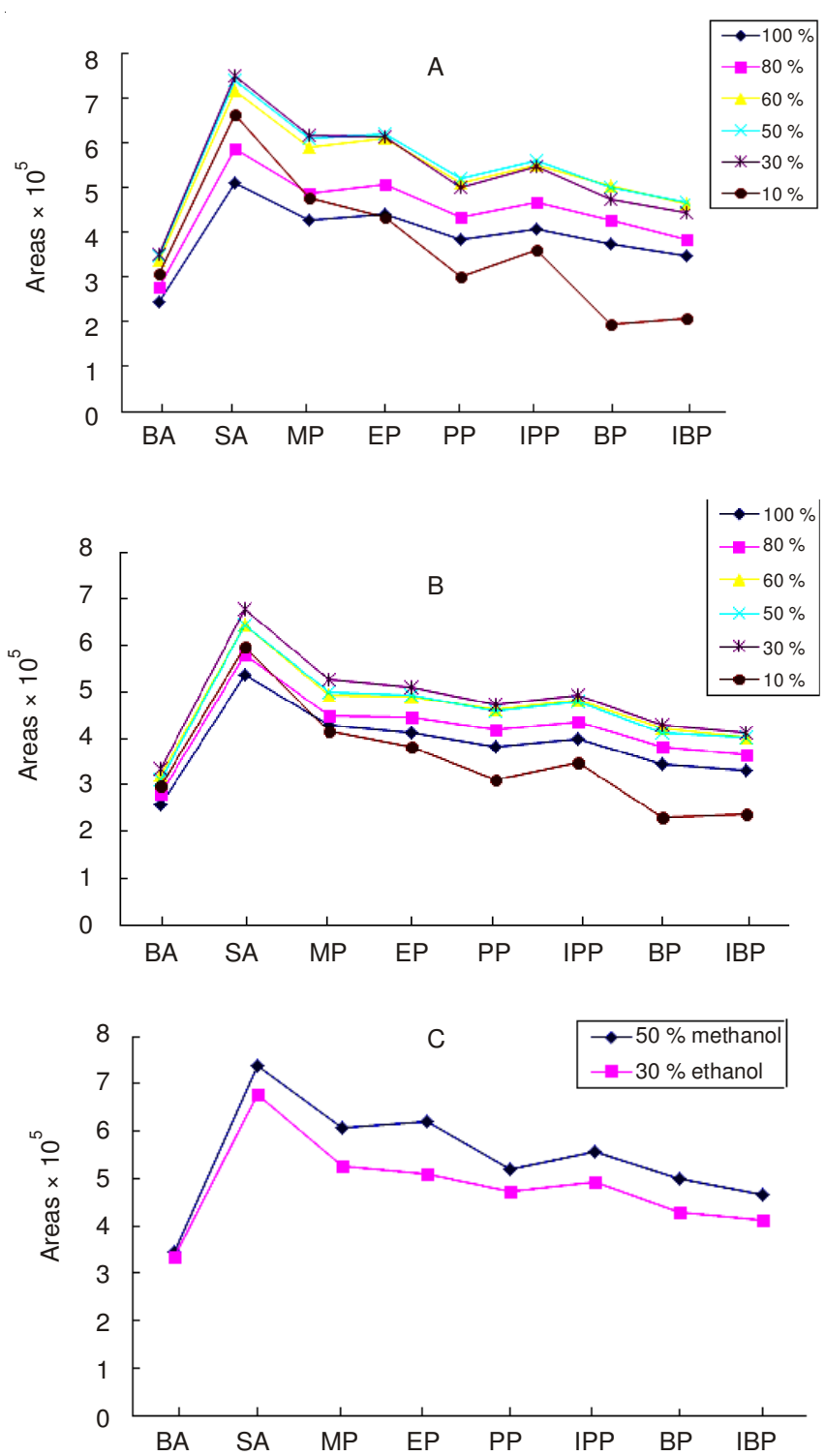

Fig. 1. Effect of extractants on the extraction of the eight studied components in feeds A. Effect of different ratio methanol and water as extractant on the extraction of the eight components in feeds. The percentage in the figure means the percentage content of methanol in methanol-water. B. Effect of different ratio ethanol and water as extractant on the extraction of the eight components in feeds. The percentage in the figure means the percentage content of ethanol in ethanol-water. C. Effect of 50\% methanol-50\% water and $30 \%$ ethanol- $70 \%$ water on the extraction of the eight components in feeds

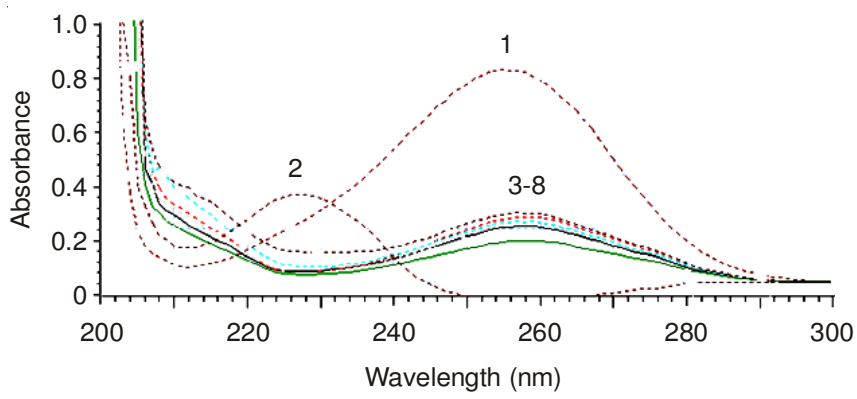

Fig. 2. UV spectrum of the eight preservatives 1. sorbic acid, 2. benzoic acid, 3. methylparaben, 4. ethylparaben, 5. iso-propylparaben, 6. propylparaben, 7. iso-butylparaben, 8 . butylparaben three peaks of benzoic acid, sorbic acid and methyl paraben overlapped partly. The baseline separation of the eight components was achieved under the ratio of 55:45, but the run time was $25 \mathrm{~min}$. To shorten the elution time of parabens after the successful elution of benzoic acid and sorbic acid, a gradient elution was used. The volume ratio of methanol and $0.05 \mathrm{moL} / \mathrm{L}$ ammonium formate solution was changed from 55 to $65 \%$.

Optimization of mobile phase $\mathbf{p H}$ : $\mathrm{pH}$ value was very important for the separation of the eight preservatives, especially for sorbic acid and benzoic acid. Six different values of $\mathrm{pH}$ were investigated, including $\mathrm{pH} 3,4,4.5,5,5.5,6$. The results showed that at $\mathrm{pH} 3$, the peaks of sorbic acid and methyl paraben overlapped. At $\mathrm{pH} 4$, the sorbic acid peak overlapped with the benzoic acid peak. And at $\mathrm{pH} 6$, the sorbic acid peak overlapped partly with the methyl paraben peak. The eight components were separated at $\mathrm{pH} 4.50,5$ and 5.5. To achieve an adequate resolution between all eluted peaks, $\mathrm{pH} 4.5$ was chosen.

Under the stated experimental conditions, a chromatogram with good peak shape with a steady baseline required for the simultaneous analysis of the eight preservatives within $13 \mathrm{~min}$ was obtained (Fig. 3). The separation time was found to be much shorter than that reported previously ${ }^{19}$ and the baseline separation of the eight preservatives was achieved.

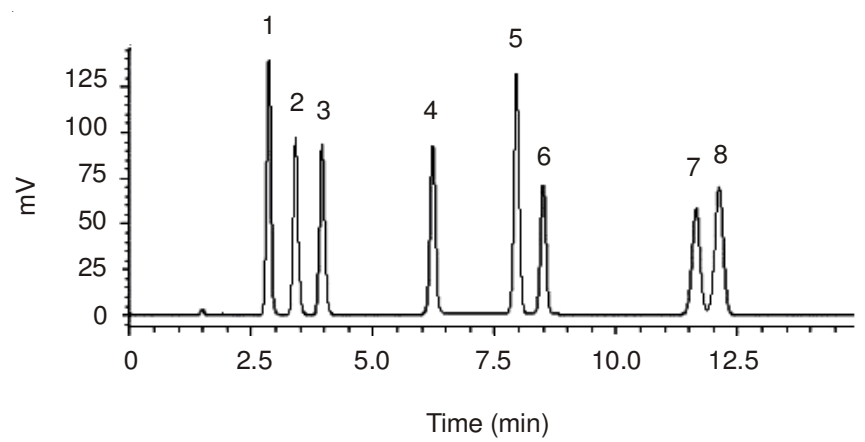

Fig. 3. Chromatogram of the standard solution peaks: 1. benzoic acid, 2 . sorbic acid, 3. methylparaben, 4. ethylparaben, 5. iso-propylparaben, 6. propylparaben, 7. iso-butylparaben, 8. butylparaben. The mixture standard solution including $5.2 \mu \mathrm{g} / \mathrm{mL}$ for sorbic acid, 80 $\mu \mathrm{g} / \mathrm{mL}$ for benzoic acid, $100 \mu \mathrm{g} / \mathrm{mL}$ for methylparaben, ethylparaben and iso-propylparaben, $120 \mu \mathrm{g} / \mathrm{mL}$ for propylparaben and isobutylparaben, $160 \mu \mathrm{g} / \mathrm{mL}$ for butylparaben

Linearity and detection limit: Under the selected conditions, the linearity was assessed using the different concentrations of standard solution in the range of 0.05-200 $\mu \mathrm{g} / \mathrm{mL}$. Analytical curves were obtained by plotting peak area $v s$. the concentrations of respective substances. Detection limits were evaluated on the basis of a signal-to-noise ratio of 3. As was shown in Table-1, straight regression lines with correlation coefficients above 0.9991 were obtained. The detection limits of the eight preservatives were $0.05 \mu \mathrm{g} / \mathrm{mL}$ for sorbic acid, $0.5 \mu \mathrm{g} / \mathrm{mL}$ for benzoic acid, $0.3 \mu \mathrm{g} / \mathrm{mL}$ for methyl paraben, ethyl paraben, butyl paraben and propyl paraben, $0.1 \mu \mathrm{g} / \mathrm{mL}$ for iso-propyl paraben and $0.2 \mu \mathrm{g} / \mathrm{mL}$ for iso-butyl paraben, respectively. Detection limits for the eight preservatives were found to be lower than $1-2 \mu \mathrm{g} / \mathrm{mL}$ for the components reported previously ${ }^{19}$. 
TABLE-1

LINEARITY AND DETECTION LIMIT OF THE EIGHT PRESERVATIVES

\begin{tabular}{llccc}
\hline \multicolumn{1}{c}{ Components } & Linear equation & Correlation coefficient & Linear range $(\mu \mathrm{g} / \mathrm{mL})$ & Detection limit $(\mu \mathrm{g} / \mathrm{mL})$ \\
\hline Benzoic acid & $\mathrm{y}=36579 \mathrm{x}+2632.9$ & 0.9991 & $1.0-200$ & 0.50 \\
Sorbic acid & $\mathrm{y}=171506 \mathrm{x}+14893$ & 0.9993 & $0.1-150$ & 0.05 \\
Methyl paraben & $\mathrm{y}=20556 \mathrm{x}+5971.0$ & 0.9995 & $0.5-200$ & 0.30 \\
Ethyl paraben & $\mathrm{y}=22033 \mathrm{x}+7892.5$ & 0.9994 & $0.5-200$ & 0.30 \\
Propyl paraben & $\mathrm{y}=18533 \mathrm{x}+1836.6$ & 0.9996 & $0.5-200$ & 0.30 \\
iso-Propyl paraben & $\mathrm{y}=32055 \mathrm{x}+4030.6$ & 0.9996 & $0.2-200$ & 0.10 \\
Butyl paraben & $\mathrm{y}=16793 \mathrm{x}+6932.3$ & 0.9996 & $0.5-200$ & 0.30 \\
iso-Butyl paraben & $\mathrm{y}=16571 \mathrm{x}+8859.1$ & 0.9997 & $0.5-200$ & 0.20 \\
\hline
\end{tabular}

TABLE-2

RECOVERY AND PRECISION OF THE EIGHT PRESERVATIVES $(n=5)$

\begin{tabular}{|c|c|c|c|c|}
\hline \multirow{2}{*}{ Components } & \multicolumn{2}{|c|}{ Amount added levels $(\mu \mathrm{g} / \mathrm{mL})$} & \multirow{2}{*}{ Average recoveries (\%) } & \multirow{2}{*}{$\operatorname{RSD}(\%)$} \\
\hline & Added & Found & & \\
\hline \multirow{2}{*}{ Benzoic acid } & 10 & $8.69-9.50$ & $86.9-95.0$ & $1.8-3.3$ \\
\hline & 100 & 87.6-95.0 & $87.6-95.0$ & $2.5-3.6$ \\
\hline \multirow{2}{*}{ Sorbic acid } & 1 & $0.818-0.870$ & $81.8-87.0$ & $2.4-3.4$ \\
\hline & 10 & $8.08-8.96$ & $80.8-89.6$ & $2.3-3.0$ \\
\hline \multirow{2}{*}{ Methyl paraben } & 5 & $4.55-4.95$ & $91.1-99.1$ & $3.3-4.0$ \\
\hline & 50 & $42.2-47.9$ & $84.5-95.8$ & $2.0-3.5$ \\
\hline \multirow{2}{*}{ Ethyl paraben } & 5 & $4.61-5.04$ & $92.2-100.8$ & $3.6-4.2$ \\
\hline & 50 & $43.1-45.4$ & $86.2-90.8$ & $1.2-2.2$ \\
\hline \multirow{2}{*}{ Propyl paraben } & 5 & $4.54-5.05$ & $90.7-101.0$ & $3.2-4.2$ \\
\hline & 50 & $47.2-50.1$ & $94.4-100.2$ & $2.3-2.7$ \\
\hline \multirow{2}{*}{ iso-Propyl paraben } & 2 & $1.66-1.83$ & $83.0-91.5$ & $1.8-2.5$ \\
\hline & 20 & $17.1-19.0$ & $85.5-95.0$ & $1.1-2.7$ \\
\hline \multirow{2}{*}{ Butyl paraben } & 5 & $4.56-5.02$ & $91.2-100.4$ & $2.8-3.8$ \\
\hline & 50 & $51.6-53.7$ & $103.2-107.4$ & $1.2-1.9$ \\
\hline \multirow{2}{*}{ iso-Butyl paraben } & 5 & $4.56-4.95$ & $91.1-99.0$ & $1.4-1.8$ \\
\hline & 50 & $44.1-47.9$ & $88.2-95.8$ & $3.8-4.3$ \\
\hline
\end{tabular}

Recovery and precision: The recovery and precision of the method were tested by adding the standard solution at low and high concentration in feed samples. The concentration levels were 1 and $10 \mu \mathrm{g} / \mathrm{mL}$ for sorbic acid, 10 and $100 \mu \mathrm{g} / \mathrm{mL}$ for benzoic acid, 5 and $50 \mu \mathrm{g} / \mathrm{mL}$ for methyl paraben, ethyl paraben, propyl paraben, butyl paraben and iso-butyl paraben, 2 and $20 \mu \mathrm{g} / \mathrm{mL}$ for iso-propyl paraben. The average recoveries were between $80.8 \%$ and $107.4 \%$ and the relative standard deviations (RSDs \%) were less than $5 \%$ (Table-2).

Application of the method in feed samples: In order to examine the studied compound residues in feeds, 12 samples of pig feed, chicken feed, cow feed and premix feed were determined using this method. Peak identification of the preservatives in feed was based on the comparison between the retention time of standard compounds and was confirmed by spiking known standard compounds to the sample. The results were that two components benzoic acid and ethyl paraben were found in pig feed and premix feed, but anyone of the eight components was not found in other feeds. The typical chromatograms were shown in Fig. 4A and B.

\section{Conclusion}

A fast and sensitive method for simultaneous analysis and determination of the eight preservatives by HPLC was developed. After optimization of the conditions of feed sample preparation, the composition of the mobile phase, $\mathrm{pH}$ and the detection wavelength, baseline separation of all the eight preservatives was obtained within $13 \mathrm{~min}$. In addition, the
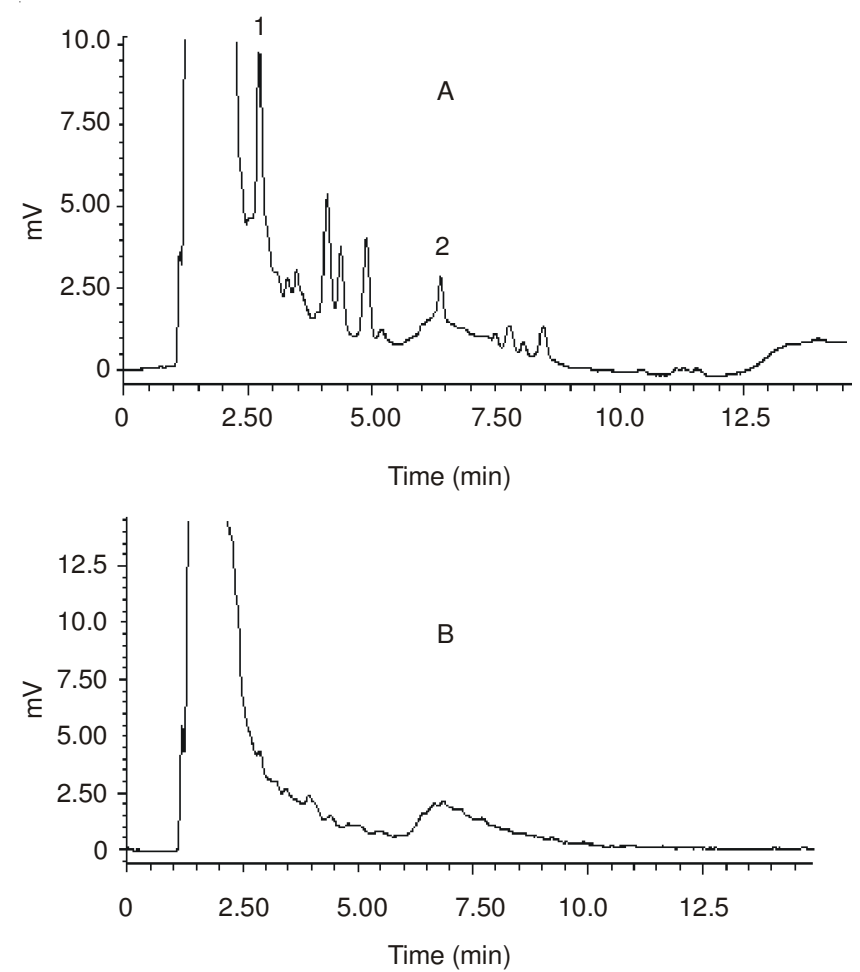

Fig. 4. Chromatograms of feed samples A. Chromatogram of premix feed sample. 1- benzoic acid 2- ethylparaben The concentration of benzoic acid in premix feed sample was $1.35 \mathrm{~g} / \mathrm{kg}$, the concentration of ethylparaben was $1.80 \mathrm{~g} / \mathrm{kg}$. B. Chromatogram of cow feed sample 
proposed method gave excellent results in analysis of eight preservatives in various types of feeds. It provides a promising and convenient entry to fast monitor the use of permitted preservatives and can be applied to self-control used by manufacturers and detected by supervision department.

\section{ACKNOWLEDGEMENTS}

This research was financially supported by National Science and Technology Support Project of China (Project No. 2013BAD10B03) and National Natural Science Foundation of China (Project No. 31101358). The feed samples were generously donated by Hebei Institute of Food Quality Supervision, Inspection and Research.

\section{REFERENCES}

1. J.M. Tong, Feed Additive Manual, China's Agriculture Press, Beijing, pp. 315-329 (2001).

2. M.R. Lee, C.Y. Lin, Z.G. Li and T.F. Tsai, J. Chromatogr. A, 1120, 244 (2006).

3. T.J. Yang, F.J. Tsai, C.Y. Chen, T.C.C. Yang and M.R. Lee, J. Anal. Chim. Acta, 668, 188 (2010).

4. S.A.V. Tfouni and M.C.F. Toledo, J. Food Control, 13, 117 (2002).

5. G. Grosa, E.D. Grosso, R. Russo and G. Allegrone, J. Pharm. Biomed. Anal., 41, 798 (2006).
6. P.Y. Wang, Y. Zhou, L. Huang, H. Zhao, A. Chen and H.Y. Zhang, J. Zhejiang Ocean Univ. (Nat. Sci.), 4, 425 (2008).

7. I. Martins, F.C. Carreira, L.S. Canaes, F.A. de Souza Campos Jr., L.M. da Silva Cruz and S. Rath, Talanta, 85, 1 (2011).

8. W.H. Gao and C. Legido-quigley, J. Chromatogr. A, 1218, 4307 (2011).

9. Y. Pan, B. Li, H.K. Zhu, X. Feng, N. Zhu and Z.R. Niu, J. Food Res. Develop., 2, 105 (2011)

10. J. Xia, J.X. Zhang, H. Li, L. Yang and C.M. Wu, J. Food Sci., 14, 219 (2011).

11. Y. Ling, X.G. Chu, F. Zhang, Q. Chen, Y. F. Zhao and Y.N. Wu, Chin. J. Chromatogr., 8, 723 (2011).

12. M. A. Farajzdeh, D. Djozan and R. B. Fazeli, Talanta, 81, 1360 (2010).

13. H.-B. Lee, T.E. Peart and M.L. Svoboda, J. Chromatogr. A, 1094, 122 (2005).

14. Q. Chen, J. R. Huang and Y. Ling, Chin. J. Anal. Chem., 5, 723 (2011) (in Chinese).

15. H.-Y. Huang, Y.-C. Lai, C.-W. Chiu and J.-M. Yeh, J. Chromatogr. A, 993, 153 (2003).

16. S.L. He, Y.F. Zhao, Z.W. Zhu, H.W. Liu, M.X. Li, Y.H. Shao and Q.K. Zhuang, Talanta, 69, 166 (2006).

17. Y. Gao, Y. Z. He, H.Y. Xie and D.S. Ling, Chin. J. Anal. Chem., 11, 1625 (2010) (in Chinese).

18. B. Saad, M.F. Bari, M.I. Saleh, K. Ahmad and M.K.M. Talib, J. Chromatogr. A, 1073, 393 (2005).

19. H.M. Yang, Y.Q. Liu, H. Wang and Q.L. Guo, J. China Condiment., 5, 94 (2011). 